\title{
Interprofessional team management in pediatric critical care: some challenges and possible solutions
}

This article was published in the following Dove Press journal:

Journal of Multidisciplinary Healthcare

24 February 2016

Number of times this article has been viewed

\author{
Martin Stocker \\ Sina B Pilgrim² \\ Margarita Burmester ${ }^{3}$ \\ Meredith L Allen ${ }^{4}$ \\ Wim H Gijselaers ${ }^{5}$ \\ 'Neonatal and Pediatric Intensive \\ Care Unit, Children's Hospital \\ Lucerne, Lucerne, ${ }^{2}$ Pediatric \\ Intensive Care, University Children's \\ Hospital Berne, Berne, Switzerland; \\ ${ }^{3}$ Pediatric Intensive Care Unit, \\ Royal Brompton Hospital, London, \\ UK; ${ }^{4}$ Department of Pediatrics, The \\ Royal Children's Hospital, Victoria, \\ Australia; ${ }^{5}$ Educational Research and \\ Development, School of Business and \\ Economics, Maastricht University, \\ Maastricht, the Netherlands
}

Correspondence: Martin Stocker Neonatal and Pediatric Intensive Care Unit, Children's Hospital Lucerne, $\mathrm{CH}-6000$ Lucerne 16, Switzerland $\mathrm{Tel}+4|4| 205323$ I

Fax +4I 4I 2053295

Email martin.stocker@luks.ch
Background: Aiming for and ensuring effective patient safety is a major priority in the management and culture of every health care organization. The pediatric intensive care unit (PICU) has become a workplace with a high diversity of multidisciplinary physicians and professionals. Therefore, delivery of high-quality care with optimal patient safety in a PICU is dependent on effective interprofessional team management. Nevertheless, ineffective interprofessional teamwork remains ubiquitous.

Methods: We based our review on the framework for interprofessional teamwork recently published in association with the UK Centre for Advancement of Interprofessional Education. Articles were selected to achieve better understanding and to include and translate new ideas and concepts.

Findings: The barrier between autonomous nurses and doctors in the PICU within their silos of specialization, the failure of shared mental models, a culture of disrespect, and the lack of empowering parents as team members preclude interprofessional team management and patient safety. A mindset of individual responsibility and accountability embedded in a network of equivalent partners, including the patient and their family members, is required to achieve optimal interprofessional care. Second, working competently as an interprofessional team is a learning process. Working declared as a learning process, psychological safety, and speaking up are pivotal factors to learning in daily practice. Finally, changes in small steps at the level of the microlevel unit are the bases to improve interprofessional team management and patient safety. Once small things with potential impact can be changed in one's own unit, engagement of health care professionals occurs and projects become accepted.

Conclusion: Bottom-up patient safety initiatives encouraging participation of every single care provider by learning effective interprofessional team management within daily practice may be an effective way of fostering patient safety.

Keywords: pediatric intensive care unit, patient safety, interprofessional team management, teamwork, psychological safety, organizational learning

\section{Background and relevance Pediatric critical care is dependent on interprofessional team management}

Pediatric critical care has evolved within the past few decades, and the state-of-the-art pediatric intensive care unit (PICU) has become a workplace involving a high diversity of multidisciplinary physicians and professionals. ${ }^{1,2}$ The example of a newborn with congenital aortic isthmus stenosis with the complication of an ischemic necrotizing enterocolitis as a typical patient in a PICU shows that up to ten medical disciplines 
and $>20$ health care professionals are involved in the care of this patient within 2 or 3 days (Figure 1). Therefore, delivery of high-quality care with optimal patient safety is dependent on effective interprofessional team management, and pediatric intensive care may serve as an illustrative example of this inevitable requirement in modern medicine. ${ }^{1-5}$

\section{Patient safety is dependent on interprofessional team management}

More than one-third of patient safety-related hospital deaths in UK between 2010 and 2012 were due to mismanagement of patient deterioration. ${ }^{6} \mathrm{Up}$ to $16 \%$ of hospitalized patients in developed countries experience harm from adverse events. The report "To Err is Human Building a Safer Health System" estimated that 44,000-98,000 patients die every year in the USA due to medical errors. ${ }^{7,8}$ Research consistently shows that competent, interprofessional teamwork is pivotal to patient safety. ${ }^{9,10}$ With the exponential increase in knowledge, the progressive specialization of health care professionals, and the declining working hours of physicians, trends in health care require an increasing interdependence of all health care professionals. ${ }^{11}$ However, reviews regarding error management in hospitals emphasize that ineffective interprofessional teamwork remains ubiquitous, despite health professionals recognizing the importance of interprofessional teamwork. ${ }^{7,9,12-14}$ Therefore, improving patient safety is an inevitable requirement for every health care organization and

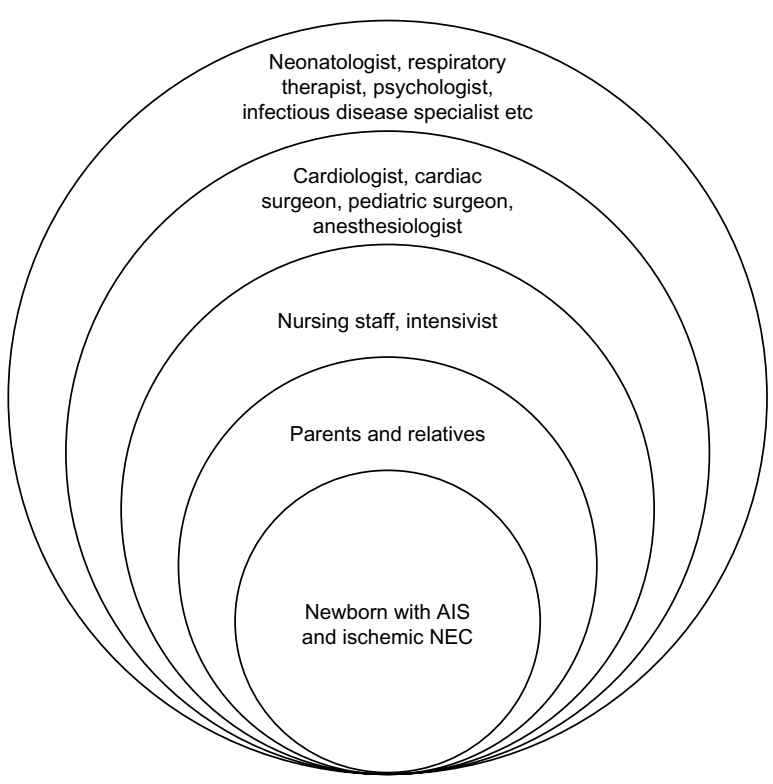

Figure I Interprofessional team management at the pediatric intensive care unit. Notes: The example of a newborn with congenital AIS with a complication of an ischemic NEC shows the high diversity of multidisciplinary physicians and professionals involved at the pediatric intensive care unit.

Abbreviations: AIS, aortic isthmus stenosis; NEC, necrotizing enterocolitis. may serve as universal outcome of effective interprofessional team management.

\section{Conceptual framework of interprofessional team management}

Interprofessional care is defined as the provision of collaborative and integrated health care among professionals derived from numerous disciplines and professions with various backgrounds in training and experience in response to the patient's needs. ${ }^{15}$ This article builds on the interprofessional teamwork framework recently published in association with the UK Centre for Advancement of Interprofessional Education (CAIPE). ${ }^{9}$ The CAIPE framework was used for this review because it puts the focus on interprofessional teamwork across different national and clinical contexts of health care. ${ }^{9}$ The CAIPE framework identifies three key areas, each contributing to interprofessional teamwork (Figure 2): 1) relational factors; 2) processual factors; and 3 ) organizational and contextual factors. Relational factors describe the mindset and affect the relationship between professionals. ${ }^{9}$ Power, hierarchy, and team composition, together with team roles, are key elements in determining the relationships shared by health care providers according to this framework. ${ }^{9}$ Processual factors describe the processes involved in teamwork. ${ }^{9}$ Working competently as a team does not just occur, it rather is a learning process. ${ }^{12,16,17}$ Learning in health care systems means being part of a highly complex system of activities, routines and rituals, as well as roles and rules with a high load of unpredictability and urgency. These factors coincide with the processual factors described in the framework. ${ }^{9}$ Organizational support, leadership, and contextual culture are responsible for the organizational environment and are considered to be important factors for interprofessional team management. ${ }^{9}$

\section{Aim}

Due to the critical interdependence of high-quality pediatric critical care and optimal patient safety in interprofessional team management, we aim to describe and discuss challenges in and possible solutions of interprofessional team management in pediatric critical care promoting patient safety.

\section{Methods}

\section{Search strategy and selection criteria}

Data were collected through searches of PubMed and EMBASE, as well as from references from full-text assessed articles, using "patient safety" and "team management 


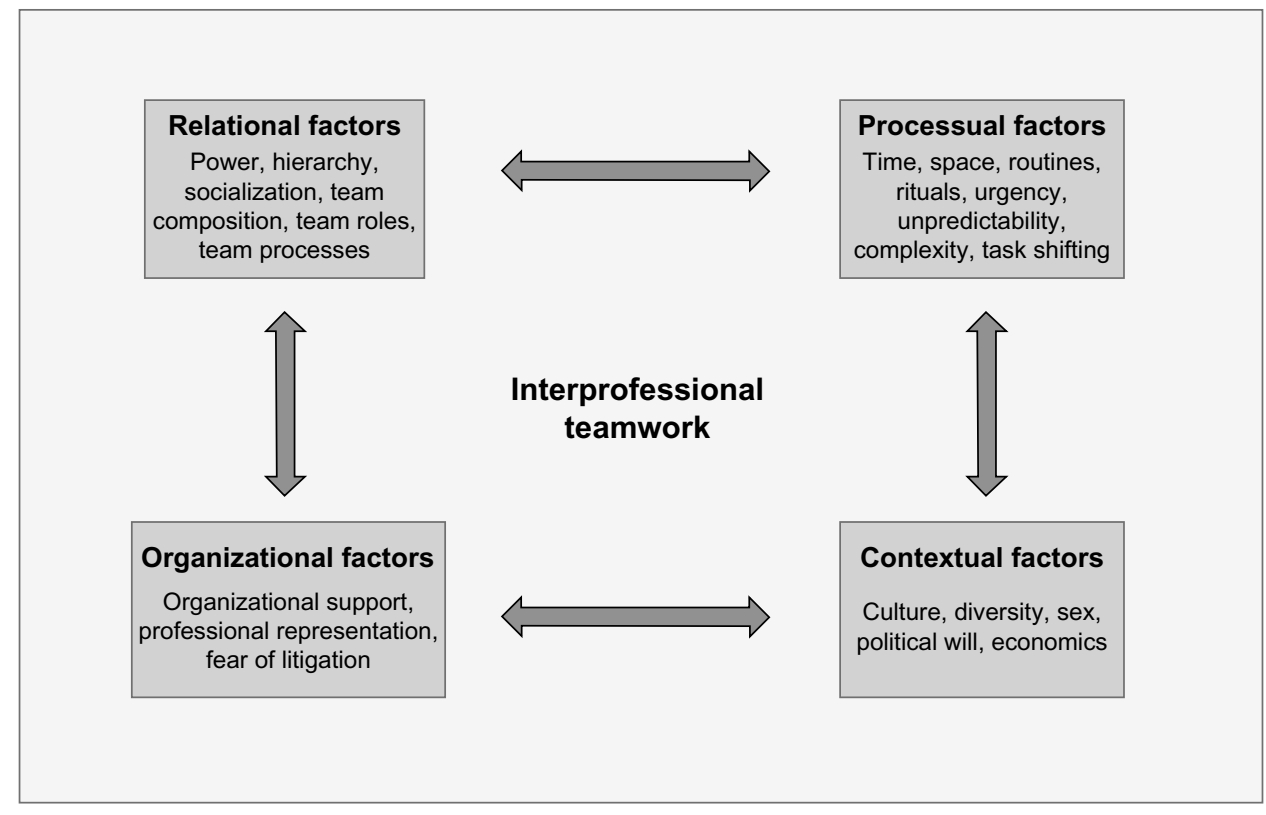

Figure 2 Conceptual framework of interprofessional teamwork.

Note: Reproduced from Reeves S, Lewin S, Espin S, Zwarenstein M. A Conceptual Framework for Interprofessional Teamwork. Chichester, West Sussex; Ames, IA: John Wiley and Sons; $2010 .{ }^{9}$ With permission from John Wiley and Sons, Copyright @ 2010.

and/or teamwork" as basic search terms, combined with search terms according to the three key areas of the CAIPE framework (Figure 2). ${ }^{9}$ To review the relational factors, we focused on the ideal mindset and relationships of different health care providers for interprofessional teamwork within the hierarchical system in a PICU. Research has identified the importance of factors affecting team relations and attitudes of health care providers toward team management in explaining efficient clinical performance and patient safety. ${ }^{9,18}$ Therefore, we used the search terms "power and/or hierarchy" and "team composition and/or team roles". To review processual factors, we focused on the mandatory learning process in terms of how competent interprofessional teamwork is carried out at the same time as delivering a service within a complex health care system as a PICU and used the search terms "team-based learning and/or organizational learning" and "learning from failure". Meta-analyses demonstrated a clear relationship between team processes and clinical performance. ${ }^{19,20}$ In addition, highly reliable organizational learning is associated with high-performance team management and patient safety. ${ }^{16,17,21-27}$ Finally, to review organizational and contextual factors, we focused on leadership actions and culture change for interprofessional team management and patient safety and used the search terms "leadership" and "culture change" (Figure 3). Studies regarding implementation of patient safety initiatives conclude that involvement of high-level leadership and culture change are prerequisites for efficient implementation. ${ }^{13,17,28-32}$ Articles published in
English, German, or French between January 2000 and June 2015 were included. Articles were selected based on achieving a conceptual review to achieve better understanding and to include and apply new ideas and concepts. This review is deliberately selective rather than systematic, and it relies on the approach of literature synthesis to provide a new perspective rather than a systematic overview. ${ }^{33}$

\section{Challenges and findings Relational factors: power and hierarchy Challenge}

All physicians and health care workers caring for patients have to be competent in terms of knowledge and skills. They are responsible for their performance, and every health care provider has to acknowledge individual gaps to direct his/her learning. This conventional, individualcentered with expertise as a skill that individuals acquire and hold is essential to drive individual accountability and responsibility. ${ }^{12}$ Over the past few decades, the dominant scenario was of competence fostering professional autonomy. Individual autonomy, in conjunction with the historically hierarchical system of health care organizations, resulted in sovereign power with limited participation as the predominant form of power in hospitals. ${ }^{12,34-39}$ Sovereign power and professional autonomy are forces creating silos (systems that operate in isolation from others) of specialization, with independent physicians impeding interprofessional team management. 


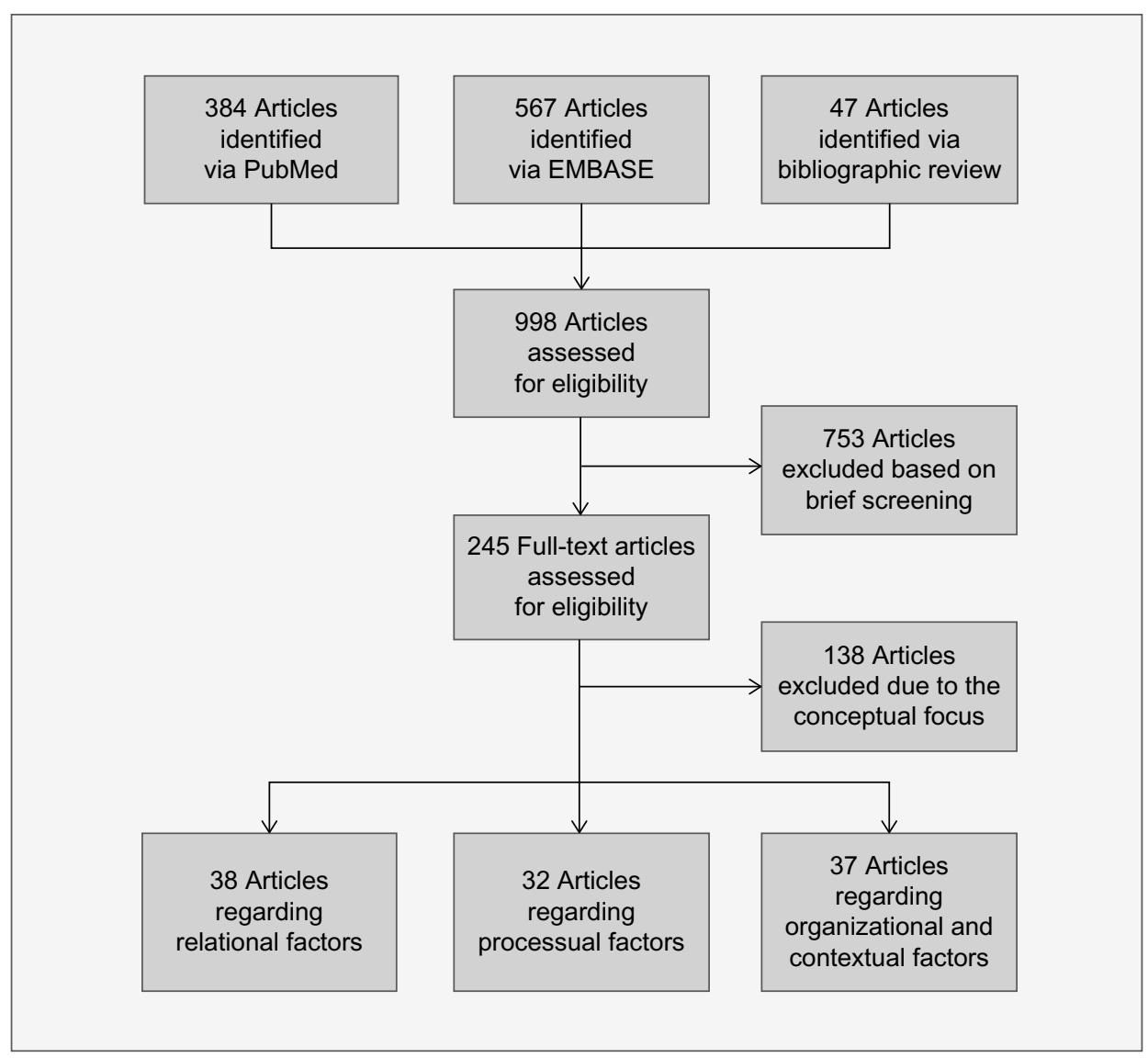

Figure 3 Data sources.

\section{Findings}

Our findings from safety literature show how requests emerge to abandon professional autonomy to overcome the barrier of silos and to work toward a coordinated team performance. ${ }^{34,40-42}$ Research consistently shows that in clinical teams with members focused on autonomy and individual responsibility, important coordinating mechanisms such as effective communication, shared mental models, mutual trust, effective followership, including independent, critical thinking and active participation, as well as leadership, are lacking. ${ }^{43-49} \mathrm{~A}$ shared mental model represents "individually held knowledge structures that help team members function collaboratively in their environments". ${ }^{50}$ Shared mental models constitute a key mechanism for effective team management, enabling team members to reflect and reason about their own situation as well as the situation of other team members. ${ }^{43-49}$ A physicians' self-esteem of independency with high individual autonomy contrasts the interdependency of shared mental models and mutual trust, in addition to hampering efficient communication and followership with nursing staff, junior doctors, and allied health professionals..$^{35}$ Therefore, tension occurs while being a leader as the responsible physician and simultaneously being a team member in an interprofessional group of health care providers. ${ }^{40,48,51-53}$ Nevertheless, an effective clinical team is the foundation of high performance, even in highly specialized areas such as pediatric cardiac surgery that demand individual surgical skills. ${ }^{54}$ In addition, in the current global world, health care providers educated in various regions of the world are working together in PICUs. There are no studies published in health care regarding the importance of considering cultural differences, but comparison among crewmembers in the airline industry shows that sex, language, religion, social status, age, and experience affect team interactions in different culture-dependent ways. ${ }^{41,55}$

\section{Relational factors: team composition and roles Challenge}

A PICU team with a high variability of training and experience, in addition to shifting roles at work, needs to have different competencies compared to a steadily operating team. As a consequence, no standard set of teamwork competencies may serve for every context. Nevertheless, building and supporting an effective clinical team is vital for high-quality care, 
especially in an acute health care setting such as pediatric intensive care. ${ }^{43-49}$ Due to different priorities and perspectives, tension occurs between senior and junior health care providers, physicians and nurses, and between parents of a child in the PICU and hospital staff. ${ }^{35,56-58}$

\section{Findings}

Research consistently shows that working successfully and efficiently together is probably rather subject to personal attitude than on specific clinical knowledge and skills. ${ }^{35,45-47,49,51,56,59}$ This is illustrated in a qualitative study with interprofessional health care providers in a neonatal intensive care unit, which described interpersonal characteristics as main factors influencing team management. ${ }^{60}$ Empirical research shows that creating a culture of respect, improving interprofessional communication, building flat hierarchies within teams, and interprofessional supervision of junior health care providers are important strategies to overcome barriers to effective team management. ${ }^{35,51,56,57,60-62}$ In modern pediatric critical care, the pediatric intensivist has become the only generalist within the highly diverse group of multidisciplinary physicians. One of the inherent duties of this role is to enhance and facilitate multidisciplinary collaboration and exchange (Figure 1). ${ }^{63}$ This is further emphasized in the current debate regarding the organization of pediatric cardiac intensive care: a recently published review concludes that a dedicated pediatric cardiac intensive care under the guidance of cardiologists and cardiac surgeons is not superior compared to a mixed PICU under the guidance of intensivists. The higher expertise in cardiac care through cardiologists and cardiac surgeons may be compensated with better team management and higher competence in general pediatric intensive care through pediatric intensivists. ${ }^{64}$ Regarding team composition, there is a growing plea by patient organizations, supported by medical literature, that the patient or relatives should be empowered, encouraged, and trusted as being part of the caring team. ${ }^{65,66}$ Parents of a sick child in a PICU are the only persistent team members; they have the highest interest in a good outcome; and they are the primary source of information. ${ }^{67,68}$ Reports of relatives of patients involved in critical patient safety incidents claim that their warning voices regarding experienced clinical deterioration were not heard by health professionals. ${ }^{58,69}$ This demonstrates that relatives of patients are currently often not seen as true team members. ${ }^{66}$

\section{Processual factors: learning while working Challenge}

How is it possible for the individual health care professional to support and learn competent, interprofessional team management within the busy daily clinical routine together with diverse team members of all levels of expertise? Table 1 outlines the daily clinical reality of a physician or nurse on call at the PICU.

\section{Findings}

According to the literature, learning while working is critical for sustained high performance in complex situations with potential hazardous outcomes and is associated with highly effective team management and patient safety. ${ }^{16,17,22,25-27,70}$ Research consistently shows that psychological safety of the individual health care professional is the single most important factor for learning while working, fostering active participation, critical thinking, effective communication, and speaking up..$^{21,25,71}$ Although reasonable and obvious, these behaviors are rare in health care organizations because they do not evolve naturally. 16,21,22,25,72 In addition, research shows that failure to speak up is another important factor that impedes learning while working and contributes to communication errors in hospitals. ${ }^{25,71,73-75}$ Speaking up allows everyone to communicate with everyone else whenever they believe it is important and whatever the message is. Nevertheless, due to hierarchical barriers and contextual factors, speaking up may be a difficult task. ${ }^{73-75}$ Edmondson's ${ }^{21,25,72}$ seminal works on organizational learning based on research into health care systems and other industries identified four

Table I Daily challenges in the PICU

\begin{tabular}{|c|c|}
\hline Challenges & Examples in the PICU \\
\hline $\begin{array}{l}\text { Health care providers have to } \\
\text { work on multiple objectives with } \\
\text { minimal oversight }\end{array}$ & $\begin{array}{l}\text { Health care providers care for } \\
\text { different patients at the same time }\end{array}$ \\
\hline $\begin{array}{l}\text { Health care providers must shift } \\
\text { from one situation to another }\end{array}$ & $\begin{array}{l}\text { Health care providers shift from the } \\
\text { situation of a girl with suspected } \\
\text { meningitis to the } 2 \text {-year-old boy } \\
\text { vomiting blood }\end{array}$ \\
\hline $\begin{array}{l}\text { There is a need to include } \\
\text { different perspectives from } \\
\text { various disciplines }\end{array}$ & $\begin{array}{l}\text { Health care providers consider } \\
\text { various types of information } \\
\text { from the history of the patients, } \\
\text { laboratory results, and the } \\
\text { consultations with specialists }\end{array}$ \\
\hline $\begin{array}{l}\text { There is a need to collaborate } \\
\text { across dispersed locations }\end{array}$ & $\begin{array}{l}\text { The pediatric surgeon is in the } \\
\text { operating theater and the infectious } \\
\text { disease specialist comes from the } \\
\text { outpatient department }\end{array}$ \\
\hline $\begin{array}{l}\text { Preplanned coordination is } \\
\text { impossible }\end{array}$ & $\begin{array}{l}\text { Many patients are presenting without } \\
\text { appointment at very short notice }\end{array}$ \\
\hline $\begin{array}{l}\text { Complex information must be } \\
\text { processed, synthesized, and put } \\
\text { to use quickly }\end{array}$ & $\begin{array}{l}\text { If the patient is deteriorating, health } \\
\text { care providers have to make quick } \\
\text { decisions of high importance }\end{array}$ \\
\hline
\end{tabular}

Abbreviation: PICU, pediatric intensive care unit. 
behaviors that drive and four leadership actions that foster learning while working (Table 2 and 3 ).

\section{Processual factors: learning from failure Challenge}

Learning from failure is a key element of all patient safety initiatives. Nevertheless, research shows it does not occur naturally and many organizations fail to do it. ${ }^{13,21,71,72,76,77}$ Why are some organizations able to learn from failures and others are not?

\section{Findings}

Admitting that failure is not only expected but essential and to be rewarded for further development helps care providers and their organizations to detect, discuss, and learn from failure. ${ }^{25,72,78,79}$ Psychological safety and trust are mandatory organizational conditions to empower health care workers in a hospital to report and discuss observed or performed errors and failures..$^{25,75,80-83}$ Every care provider experiencing an error or a problem has the responsibility to transfer the information to the higher organizational level. Therefore, "ideal employee" behaviors of cleaning up errors and problems unnoticed are negative for learning from failure. ${ }^{25,71}$ Belief in improvement, systematic analysis, and implementation, as well as dissemination with feedback and transparency, are other key factors facilitating learning from failure..$^{21,83-88}$ Reduction in use of invasive devices, antibiotics, and the laboratory after successful implementation of a daily safety checklist in a PICU after omission-related adverse events may highlight the importance of systematic analysis, dissemination, and transparency. ${ }^{89}$ On the other hand, if health care providers work successfully, they need to identify their success and learn why they were successful. ${ }^{90}$ This can be difficult to do as safe outcomes are expected and underlying reasons are prone to be neglected and taken for granted. ${ }^{23,91,92}$ "Learning involves understanding why things happen and why some decisions lead to specific outcomes". ${ }^{92}$

\section{Organizational and contextual factors: leadership \\ Challenge}

Multiple actions such as patient safety initiatives, patientcentered care, or interprofessional teamwork have been

Table 2 Behaviors driving learning

\section{Speaking up}

Collaboration

Experimentation

Reflection

Note: Experimentation means not expecting to be right the first time. launched to improve patient safety. ${ }^{9,10,93,94}$ Studies regarding implementation of patient safety initiatives conclude that involvement of high-level leadership is a prerequisite. ${ }^{13,28-32}$ What are important leadership principles to improve interprofessional team management for patient safety?

\section{Findings}

A recently published review of patient safety-related hospital deaths in UK concludes that "there is a disconnect between national harm reduction initiatives and areas of concern that hospital staff see as important". ${ }^{6}$ Research shows that senior health professionals at the bedside play a crucial role as role models and leaders throughout the organization, developing others' skills and shaping effective processes..$^{22,25,87,95}$ The reported impact of initiatives is often small or may even have a negative impact when clinical team members have not "bought in" to the process. ${ }^{10,14,71,87,95-97}$ Indeed, involvement and learning from front line health care providers is a key element of safety management and leadership..$^{22,25,90,98}$ Effective leadership means to be an inspiration for your coworkers, explaining why interprofessional team management is mandatory for high-quality critical care and optimal patient safety. ${ }^{25,99,100} \mathrm{On}$ the other hand, improving patient safety is a basic necessity for every doctor and health care worker caring for patients and is acknowledged as an individual responsibility. ${ }^{9,22,87,95}$ "If there is no transformation inside each of us, all structural change in the world will have no impact on our institutions". ${ }^{101}$ Patient safety is subject to voluntary participation of every single care provider, and everyone in an organization may become a leader developing new processes or other people's skills with their personality and behaviors. ${ }^{22,25,95,102,103}$ The process to be a clinical leader in a specific situation starts with individual motivation. ${ }^{103,104}$ "Empowerment is not granted by the organization, people must empower themselves". ${ }^{103}$

\section{Organizational and contextual factors: cultural change \\ Challenge}

Studies and reviews regarding effective implementation of patient safety conclude that a culture change is mandatory. ${ }^{13,17,28-32}$ Culture change is a huge operation accompanied by unpredictability and uncertainty over a long period of time..$^{25,95,105}$ What can the individual health care worker do for a culture change toward improved interprofessional team management for patient safety?

\section{Findings}

Creating a culture of respect is reported as an essential first step to enhance patients' safety. Respect and trust 
build up psychological safety for junior health care providers, facilitating communication, team management, and learning while working. ${ }^{51}$ Change in small steps as an adaptation is a learning process, and this may be initiated on an individual or team basis..$^{23,95,105}$ The report of sequential interventions improving communication through shared agreement of patients' daily goal among interprofessional health care providers in a PICU may serve as an illustrative example: During a 9-month period, the process started by implementing new daily progress notes, followed after 2-3 months by the introduction of a performance improvement dashboard, and finally completed by documenting patients' daily goals on bedside whiteboards. ${ }^{106}$ This example demonstrates a learning process in small steps facilitating a culture change toward improved communication and shared mental models. Outcomes in patient safety at the organizational level are mainly subject to the work conducted in microlevel units such as the operation theater or the intensive care unit. ${ }^{24,39,105,107-109}$ Changes in microlevel units are often directed at realistic problems and they are therefore better understood and accepted by involved care professionals, compared to initiative directives at the macrolevel unit such as the department or the hospital. ${ }^{39,105,108}$ Research shows that creating high-reliability organizations in health care often starts at a local, microlevel before moving toward standardized stages with a high level of safety for the organization..$^{39,110}$ Transparency and dissemination from the local level to the macrolevel unit is an essential step, which may only occur in dedicated learning organizations. ${ }^{22,71,95,110}$

\section{Solutions and discussion}

Our literature review suggests that competent individuals may not be necessarily competent interprofessional team members. ${ }^{12}$ Individual responsibility and accountability have to be embedded within a network of equivalent partners to achieve a cohesive team with common goals within a culture of respect. ${ }^{12,27,51-53,56}$ Shared mental models and efficient communication between team members, including parents and relatives of patients, form the basis for effective team management in a PICU. ${ }^{51,53,56,111}$

Working competently as an interprofessional team may not just happen; it is probably rather an ongoing learning process. ${ }^{12,16,17}$ The challenge is to learn simultaneously to delivering a service, and there is currently a missed opportunity to structure clinical work as a learning process to improve patient safety. ${ }^{25,36}$ Leadership actions are necessary to drive learning: if the responsible consultant physician informs the team at the start of a procedure at PICU that "nobody is without failure and errors, therefore if anything goes wrong, whoever you are, please speak up", then psychological safety for nurses or junior physicians is disclosed and barriers to speaking up are diminished. ${ }^{25}$ In health care organizations, stakes are very high and leaders may argue that focus on learning on the job is too risky. Formal, team-based learning is possible in simulation. It is a valuable option for experimentation and assessment of new actions and behaviors. Research has shown that simulated team training is effective..$^{20,47,112-117}$ In the setting of simulation training, the leadership actions listed in Table 3 are incorporated, and simulation may be an important tool facilitating learning while working. ${ }^{20,115-118}$

Achieving effective teamwork and enabling learning while working may require leadership and cultural change, which foster interprofessional team management. While cultural change is a complex undertaking for a hospital, feasible changes can be made in small units because they are easier to apply. Front line professionals working in small units have a natural commitment to delivery of high-quality care. If a consultant is keen to support learning while working in the PICU, he/she can do so as a personal, low-level initiative. Framing the situation for learning, empowering team members to speak up, and highlighting the significance of learning from failure is taking leadership action in this situation. This allows for training and equipping professionals with necessary team skills. Later on, their experiences could be shared with other teams and hospital departments. ${ }^{39,95,105,110}$

There is a growing body of literature showing effective implementation strategies to improve interprofessional care. Interprofessional workshops and educational activities, ${ }^{119-122}$ implementation of crosss-functional teams, ${ }^{123}$ simulation training, ${ }^{124-126}$ individual and team-based debriefing, feedback, coaching and mentorship,,$^{25,118,127-129}$ and $360^{\circ}$ evaluation processes $^{130}$ are reported as effective strategies to improve interprofessional team management in varying contexts of health care. Table 4 summarizes the challenges and gives examples for implementation to support patient safety through improved interprofessional team management in the PICU.

Table 3 Leadership actions for organizing to learn

Frame the situation for learning

Make it psychologically safe

Learn to learn from failure

Span occupational and cultural boundaries

Note: Reproduced from Edmondson AC, Teaming: How Organizations Learn, Innovate, and Compete in the Knowledge Economy. San Francisco, CA: John Wiley and Sons $2012 .{ }^{25}$ With permission from John Wiley and Sons, Copyright @ 2012. 
Table 4 Summary of challenges and solutions, including examples for implementation, to support patient safety through improved interprofessional team management

\begin{tabular}{|c|c|c|c|}
\hline $\begin{array}{l}\text { Key areas of } \\
\text { interprofessional } \\
\text { teamwork }\end{array}$ & Challenge & Solution & $\begin{array}{l}\text { Examples supporting } \\
\text { implementation }\end{array}$ \\
\hline $\begin{array}{l}\text { Relational factors: } \\
\text { power and hierarchy }\end{array}$ & $\begin{array}{l}\text { Sovereign power and } \\
\text { professional autonomy are forces } \\
\text { creating silos of specialization } \\
\text { impeding interprofessional team } \\
\text { management }\end{array}$ & $\begin{array}{l}\text { Individual responsibility and } \\
\text { accountability has to be embedded } \\
\text { in a network of equivalent partners } \\
\text { with a shared goal; promotion of } \\
\text { shared mental models }\end{array}$ & $\begin{array}{l}\text { Interprofessional meetings, workshops, } \\
\text { and education activities promoting } \\
\text { shared mental models; individual and } \\
\text { team-based debriefing, feedback, } \\
\text { coaching, and mentorship; } 360^{\circ} \text { feedback }\end{array}$ \\
\hline $\begin{array}{l}\text { Relational factors: team } \\
\text { composition and roles }\end{array}$ & $\begin{array}{l}\text { The tension between senior and } \\
\text { junior health care providers, } \\
\text { physicians and nurses, and } \\
\text { between parents of a child at } \\
\text { the PICU and hospital staff } \\
\text { hinders interprofessional team } \\
\text { management }\end{array}$ & $\begin{array}{l}\text { Promotion of a culture of mutual } \\
\text { respect, shared mental models, and } \\
\text { efficient communication between } \\
\text { team members, including parents } \\
\text { and relatives of patients }\end{array}$ & $\begin{array}{l}\text { Interprofessional meetings, workshops, } \\
\text { and education activities promoting a } \\
\text { culture of respect; individual and team- } \\
\text { based debriefing, feedback, coaching, } \\
\text { and mentorship; } 360^{\circ} \text { feedback; } \\
\text { communication training }\end{array}$ \\
\hline $\begin{array}{l}\text { Processual factors: } \\
\text { learning while working }\end{array}$ & $\begin{array}{l}\text { How is it possible for } \\
\text { the individual health care } \\
\text { professional to support and learn } \\
\text { competent, interprofessional } \\
\text { team management within the } \\
\text { busy daily routine workload? }\end{array}$ & $\begin{array}{l}\text { Promotion of psychological } \\
\text { safety and speaking up to support } \\
\text { learning while working }\end{array}$ & $\begin{array}{l}\text { Team-based debriefing, feedback, and } \\
\text { coaching critically questioning how to } \\
\text { do better while working; managerial } \\
\text { and leadership focus on learning while } \\
\text { working; simulation training }\end{array}$ \\
\hline $\begin{array}{l}\text { Processual factors: } \\
\text { learning from failure }\end{array}$ & $\begin{array}{l}\text { Learning from failure is a key } \\
\text { element of all patient safety } \\
\text { initiatives, but this is not } \\
\text { happening naturally and many } \\
\text { organizations fail to do so }\end{array}$ & $\begin{array}{l}\text { Acknowledgment that failure is } \\
\text { mandatory for learning; ensuring } \\
\text { psychological safety, systematic } \\
\text { analysis, and dissemination }\end{array}$ & $\begin{array}{l}\text { Managerial and leadership focus on } \\
\text { learning while working; mortality-and- } \\
\text { morbidity conference; critical incident } \\
\text { reporting system; dissemination of } \\
\text { reported errors and solutions; rewards } \\
\text { for error reporting }\end{array}$ \\
\hline $\begin{array}{l}\text { Organizational and } \\
\text { contextual factors: } \\
\text { leadership }\end{array}$ & $\begin{array}{l}\text { Impact of patient safety } \\
\text { initiatives is often small; what are } \\
\text { important leadership principles } \\
\text { to improve interprofessional } \\
\text { team management for patient } \\
\text { safety? }\end{array}$ & $\begin{array}{l}\text { Acknowledgment of front line } \\
\text { workers regarding important topics } \\
\text { and possible solutions; individual } \\
\text { willingness and motivation of every } \\
\text { health care worker for leadership } \\
\text { at every level }\end{array}$ & $\begin{array}{l}\text { Acknowledging and supporting bottom- } \\
\text { up initiatives and projects; individual } \\
\text { and team-based debriefing, feedback, } \\
\text { coaching, and mentorship; managerial } \\
\text { and leadership focus on learning while } \\
\text { working; rewards for individual projects }\end{array}$ \\
\hline $\begin{array}{l}\text { Organizational and } \\
\text { contextual factors: } \\
\text { culture change }\end{array}$ & $\begin{array}{l}\text { Culture change is prerequisite } \\
\text { for improved patient safety, } \\
\text { but culture change is a huge } \\
\text { operation surrounded with } \\
\text { unpredictability and uncertainty } \\
\text { over a long period of time }\end{array}$ & $\begin{array}{l}\text { Change in small steps as an } \\
\text { adaptation and a learning process; } \\
\text { from the microlevel unit to the } \\
\text { organization; transparency and } \\
\text { dissemination }\end{array}$ & $\begin{array}{l}\text { Acknowledging and supporting unit- } \\
\text { based initiatives and projects; individual } \\
\text { and team-based debriefing, feedback, } \\
\text { coaching, and mentorship; managerial } \\
\text { and leadership focus on learning while } \\
\text { working; rewards for unit-based projects }\end{array}$ \\
\hline
\end{tabular}

Abbreviation: PICU, pediatric intensive care unit.

\section{Limitations}

There are several limitations of our review. First, literature on team management and patient safety is extensive and not fully covered within the searched medical databases. Second, due to the broadness of the topic and the high methodological diversity of the studies, an overall generalizable systematic review and meta-analysis are not realistic. Our review is focused on the approach of literature synthesis to include knowledge and give a new perspective. Third, there are many more challenges for interprofessional team management in a PICU than reported in this review, such as unpredictability of clinical work, events of death with emotions of grief and feelings of guilt, ethical dilemmas, new medical and information technology breakthroughs, economic pressure, sex-based inequalities, or fear of litigation. Nevertheless, the challenges are chosen according to the published framework for interprofessional teamwork, and the selection is consistent with the three key areas of the framework, ensuring a broad coverage.

\section{Conclusion}

Patient safety is a top priority for every health care organization and every health care professional. Research shows that effective team management is mandatory for patient safety. The barrier between autonomous nurses and doctors in the PICU within their silos of specialization, the failure of shared 
mental models between the patient's named doctor and other health care providers caring for a child in the PICU, a culture of disrespect, and the lack of empowerment of parents and relatives as team members and acknowledging their warning voices regarding clinical deterioration may hinder interprofessional team management and patient safety. A mindset of individual responsibility and accountability embedded in a network of equivalent partners, including the patient and their family members, is required to achieve interprofessional, patient-centered care. Second, working competently as an interprofessional team is a learning process. Findings of our review show that working declared as a learning process, psychological safety, and speaking up are pivotal factors to learn in daily practice. Critically questioning how to do better while working in a psychologically safe environment allows every individual health care professional, as well as every team, to learn from both failure and success. Finally, research shows that work and changes in small steps at the scale of the microlevel unit are the bases to improve interprofessional team management and patient safety. If small things with potential impact can be changed in one's own unit, engagement of health care professionals occurs and projects become accepted. Bottom-up patient safety initiatives encouraging participation of every single care provider by learning effective interprofessional team management within daily practice may be an effective way of fostering patient safety.

\section{Acknowledgment}

There was no funding source for this review.

\section{Author contributions}

MS is responsible for the concept of the review, search strategy, and selection of articles; he has drafted the manuscript, confirms the final responsibility for the published version, and is accountable for all aspects of the work. SBP has contributed as second author to search strategy and selection of articles, has critically revised the manuscript, has given final approval for the published version, and is accountable for all aspects of the work. MB, MLA, and WHG have substantially contributed to the concept and content of the work, critically revised the manuscript, and given final approval for the published version, as well as being accountable for all aspects of the work. No person other than the authors listed has contributed significantly to the manuscript. The corresponding author confirms the final responsibility in submitting the manuscript. All authors had full access to all the data and approved the manuscript.

\section{Disclosure}

The authors report no conflicts of interest in this work.

\section{References}

1. Riley C, Poss WB, Wheeler DS. The evolving model of pediatric critical care delivery in North America. Pediatr Clin North Am. 2013;60(3):545-562.

2. Rosenberg DI, Moss MM; American College of Critical Care Medicine of the Society of Critical Care Medicine. Guidelines and levels of care for pediatric intensive care units. Crit Care Med. 2004;32(10):2117-2127.

3. Frey B, Argent A. Safe paediatric intensive care. Part 2: workplace organisation, critical incident monitoring and guidelines. Intensive Care Med. 2004;30(7):1292-1297.

4. Niedner MF, Muething SE, Sutcliffe KM. The high-reliability pediatric intensive care unit. Pediatr Clin North Am. 2013;60(3):563-580.

5. Curtis JR, Cook DJ, Wall RJ, et al. Intensive care unit quality improvement: a "how-to" guide for the interdisciplinary team. Crit Care Med. 2006;34(1):211-218.

6. Donaldson LJ, Panesar SS, Darzi A. Patient-safety-related hospital deaths in England: thematic analysis of incidents reported to a national database, 2010-2012. PLoS Med. 2014;11(6):e1001667.

7. Committee on Quality of Health Care in America; Linda KT, Corrigan JM, Donaldson MS; Institute of Medicine (U.S.). To Err is Human Building a Safer Health System. Washington, DC: National Academies Press; 2000.

8. Jha AK, Prasopa-Plaizier N, Larizgoitia I, et al; Research Priority Setting Working Group of the WHO World Alliance for Patient Safety. Research priority setting working group of the WHO world alliance for patient safety. Patient safety research: an overview of the global evidence. Qual Saf Health Care. 2010;19(1):42-47.

9. Reeves S, Lewin S, Espin S, Zwarenstein M. Interprofessional Teamwork for Health and Social Care. In: A Conceptual Framework for Interprofessional Teamwork. Chichester, West Sussex; Ames, IA: John Wiley and Sons; 2010.

10. Leape L, Berwick D, Clancy C, et al; Lucian Leape Institute at the National Patient Safety Foundation. Transforming healthcare: a safety imperative. Qual Saf Health Care. 2009;18(6):424-428.

11. Shine KI. Health care quality and how to achieve it. Acad Med. 2002;77(1):91-99

12. Lingard L. Rethinking competence in the context of teamwork. In: Hodges BD, Lingard L, editors. The Question of Competence: Reconsidering Medical Education in the Twenty-First Century. Ithaca: ILR Press; 2013:14-41.

13. Spath P. Error Reduction in Health Care a Systems Approach to Improving Patient Safety. San Francisco, CA: Jossey-Bass; 2011.

14. Leape LL, Berwick DM. Five years after to err is human: what have we learned? JAMA. 2005;293(19):2384-2390.

15. D'Amour D, Oandasan I. Interprofessionality as the field of interprofessional practice and interprofessional education: an emerging concept. J Interprof Care. 2005;19(suppl 1):8-20.

16. Firth-Cozens J. Cultures for improving patient safety through learning: the role of teamwork. Qual Health Care. 2001;10(suppl 2):ii26-ii31.

17. Singer SJ, Falwell A, Gaba DM, et al. Identifying organizational cultures that promote patient safety. Health Care Manage Rev. 2009;34(4):300-311.

18. Manser T. Teamwork and patient safety in dynamic domains of healthcare: a review of the literature. Acta Anaesthesiol Scand. 2009;53(2):143-151.

19. Schmutz J, Manser T. Do team processes really have an effect on clinical performance? A systematic literature review. Br J Anaesth. 2013;110(4):529-544.

20. Salas E, DiazGranados D, Klein C, et al. Does team training improve team performance? A meta-analysis. Hum Factors. 2008;50(6):903-933.

21. Edmondson AC. Learning from failure in health care: frequent opportunities, pervasive barriers. Qual Saf Health Care. 2004;13(suppl 2):ii3-ii9. 
22. Carroll JS, Edmondson AC. Leading organisational learning in health care. Qual Saf Health Care. 2002;11(1):51-56.

23. Reason J. Achieving a safe culture: theory and practice. Work Stress. 1998;12(3):293-306.

24. Mohr JJ, Batalden PB. Improving safety on the front lines: the role of clinical microsystems. Qual Saf Health Care. 2002;11(1):45-50.

25. Edmondson AC. Teaming: How Organizations Learn, Innovate, and Compete in the Knowledge Economy. San Francisco, CA: John Wiley and Sons; 2012.

26. Goh SC, Chan C, Kuziemsky C. Teamwork, organizational learning, patient safety and job outcomes. Int J Health Care Qual Assur. 2013;26(5):420-432.

27. Pronovost PJ, Berenholtz SM, Goeschel CA, et al. Creating high reliability in health care organizations. Health Serv Res. 2006;41(4 pt 2): 1599-1617.

28. Khatri N, Brown GD, Hicks LL. From a blame culture to a just culture in health care. Health Care Manage Rev. 2009;34(4):312-322.

29. Thomas L, Galla C. Building a culture of safety through team training and engagement. BMJ Qual Saf. 2013;22(5):425-434.

30. Weaver SJ, Rosen MA, Salas E, Baum KD, King HB. Integrating the science of team training: guidelines for continuing education. $J$ Contin Educ Health Prof. 2010;30(4):208-220.

31. Haynes AB, Weiser TG, Berry WR, et al; Safe Surgery Saves Lives Study Group. Changes in safety attitude and relationship to decreased postoperative morbidity and mortality following implementation of a checklist-based surgical safety intervention. BMJ Qual Saf. 2011;20(1):102-107.

32. Kaplan HC, Brady PW, Dritz MC, et al. The influence of context on quality improvement success in health care: a systematic review of the literature. Milbank Q. 2010;88(4):500-559.

33. Eva KW. On the limits of systematicity. Med Educ. 2008;42(9): $852-853$.

34. Chassin MR, Loeb JM. The ongoing quality improvement journey: next stop, high reliability. Health Aff (Millwood). 2011;30(4):559-568.

35. Leape LL, Shore MF, Dienstag JL, et al. Perspective: a culture of respect, part 1: the nature and causes of disrespectful behavior by physicians. Acad Med. 2012;87(7):845-852.

36. Bleakley A, Browne J. Medical Education for the Future: Identity, Power, and Location. Dordrecht: Springer; 2011.

37. Rathert C, May DR. Health care work environments, employee satisfaction, and patient safety: care provider perspectives. Health Care Manage Rev. 2007;32(1):2-11.

38. Moorman DW. On the quest for six sigma. Am J Surg. 2005;189(3): 253-258.

39. Berwick DM. A user's manual for the IOM's "Quality Chasm" report. Health Aff (Millwood). 2002;21(3):80-90.

40. Amalberti R, Auroy Y, Berwick D, Barach P. Five system barriers to achieving ultrasafe health care. Ann Intern Med. 2005;142(9): 756-764.

41. D' Agincourt-Canning LG, Kissoon N, Singal M, Pitfield AF. Culture, communication and safety: lessons from the airline industry. Indian $J$ Pediatr. 2011;78(6):703-708.

42. Roberts KH, Madsen P, Desai V, Van Stralen D. A case of the birth and death of a high reliability healthcare organisation. Qual Saf Health Care. 2005;14(3):216-220.

43. Salas E, Sims DE, Burke CS. Is there a "big five" in teamwork? Small Group Res. 2005;36:555-599.

44. Baker DP, Day R, Salas E. Teamwork as an essential component of high-reliability organizations. Health Serv Res. 2006;41(4 pt 2): 1576-1598.

45. Ezziane Z, Maruthappu M, Gawn L, Thompson EA, Athanasiou T, Warren OJ. Building effective clinical teams in healthcare. $J$ Health Organ Manag. 2012;26(4-5):428-436.

46. Manthous C, Nembhard IM, Hollingshead AB. Building effective critical care teams. Crit Care. 2011;15(4):307.

47. Salas E, Rosen MA. Building high reliability teams: progress and some reflections on teamwork training. BMJ Qual Saf. 2013;22(5):369-373.
48. Lingard L, Espin S, Evans C, Hawryluck L. The rules of the game: interprofessional collaboration on the intensive care unit team. Crit Care Lond Engl. 2004;8(6):R403-R408.

49. Hawryluck LA, Espin SL, Garwood KC, Evans CA, Lingard LA. Pulling together and pushing apart: tides of tension in the ICU team. Acad Med. 2002;77(10 suppl):S73-S76.

50. McComb S, Simpson V. The concept of shared mental models in healthcare collaboration. $J A d v$ Nurs. 2014;70(7):1479-1488.

51. Leape LL, Shore MF, Dienstag JL, et al. Perspective: a culture of respect, part 2: creating a culture of respect. Acad Med. 2012;87(7): $853-858$.

52. Thomas EJ, Sexton JB, Helmreich RL. Translating teamwork behaviours from aviation to healthcare: development of behavioural markers for neonatal resuscitation. Qual Saf Health Care. 2004;13(suppl 1): i57-i64.

53. Bedwell WL, Ramsay PS, Salas E. Helping fluid teams work: a research agenda for effective team adaptation in healthcare. Transl Behav Med. 2012;2(4):504-509.

54. Huckman RS, Pisano GP. The firm specificity of individual performance: evidence from cardiac surgery. Manag Sci. 2006;52(4):473-488.

55. Hagen JU. Confronting Mistakes: Lessons from the Aviation Industry When Dealing with Error. Basingstoke, Hampshire: Palgrave; 2013.

56. Weller J, Boyd M, Cumin D. Teams, tribes and patient safety: overcoming barriers to effective teamwork in healthcare. Postgrad Med J. 2014;90(1061):149-154.

57. Thomas EJ, Sexton JB, Helmreich RL. Discrepant attitudes about teamwork among critical care nurses and physicians. Crit Care Med. 2003;31(3):956-959.

58. Roland D. But I told you she was ill! The role of families in preventing avoidable harm in children. BMJ Qual Saf. 2015;24(3):186-187.

59. Collins JC. Good to Great: Why Some Companies Make the Leap. and Others Don't. New York, NY: Harper Business; 2001.

60. Thomas EJ, Sherwood GD, Mulhollem JL, Sexton JB, Helmreich RL. Working together in the neonatal intensive care unit: provider perspectives. J Perinatol. 2004;24(9):552-559.

61. Tamuz M, Giardina TD, Thomas EJ, Menon S, Singh H. Rethinking resident supervision to improve safety: from hierarchical to interprofessional models. J Hosp Med. 2011;6(8):445-452.

62. Manojlovich M. Nurse/physician communication through a sensemaking lens: shifting the paradigm to improve patient safety. Med Care. 2010;48(11):941-946.

63. Bion JF, Heffner JE. Challenges in the care of the acutely ill. Lancet. 2004;363(9413):970-977.

64. Hilvers PS, Thammasitboon S. Does ICU structure impact patient outcomes after congenital heart surgery? A critical appraisal of "care models and associated outcomes in congenital heart surgery" by Burstein et al (Pediatrics 2011; 127: e1482-e1489). Pediatr Crit Care Med. 2014;15(1):77-81.

65. Hallisy JA. The Empowered Patient: Hundreds of Life-Saving Facts, Action Steps and Strategies You Need to Know. 1st ed. San Francisco, CA: Bold Spirit Press; 2008.

66. Davis R, Savvopoulou M, Shergill R, Schwappach D. Predictors of healthcare professionals' attitudes towards family involvement in safetyrelevant behaviours: a cross-sectional factorial survey study. BMJ Open. 2014;4(9):e005549.

67. Joseph-Williams N, Elwyn G, Edwards A. Knowledge is not power for patients: a systematic review and thematic synthesis of patient-reported barriers and facilitators to shared decision making. Patient Educ Couns. 2014;94(3):291-309.

68. Longtin Y, Sax H, Leape LL, Sheridan SE, Donaldson L, Pittet D. Patient participation: current knowledge and applicability to patient safety. Mayo Clin Proc. 2010;85(1):53-62.

69. MAME: Mothers Againts Medical Errors [homepage on the Internet]. Supporting Victims of Medical Harm. Available from: www. mamemomsonline.org. Accessed December 16, 2014.

70. Bohmer RM, Edmondson AC. Organizational learning in health care. Health Forum J. 2001;44(2):32-35. 
71. Tucker AL, Edmondson AC. Why hospitals don't learn from failures: organizational and psychological dynamics that inhibit system change. Calif Manage Rev. 2003;45(2):55-72.

72. Edmondson AC. Strategies of learning from failure. Harv Bus Rev. 2011;89(4):48-55,137.

73. Schwappach DLB, Gehring K. Silence that can be dangerous: a vignette study to assess healthcare professionals' likelihood of speaking up about safety concerns. PLoS One. 2014;9(8):e104720.

74. Schwappach DLB, Gehring K. Trade-offs between voice and silence: a qualitative exploration of oncology staff's decisions to speak up about safety concerns. BMC Health Serv Res. 2014;14:303.

75. Okuyama A, Wagner C, Bijnen B. Speaking up for patient safety by hospital-based health care professionals: a literature review. BMC Health Serv Res. 2014;14:61.

76. Firth-Cozens J. Barriers to incident reporting. Qual Saf Health Care. 2002;11(1):7.

77. Leape LL. Reporting of adverse events. N Engl J Med. 2002;347(20): 1633-1638.

78. King A, Holder MG Jr, Ahmed RA. Errors as allies: error management training in health professions education. BMJ Qual Saf. 2013;22(6): 516-519.

79. Eva KW. Diagnostic error in medical education: where wrongs can make rights. Adv Health Sci Educ Theory Pract. 2009;14(suppl 1): 71-81.

80. Garvin DA, Edmondson AC, Gino F. Is yours a learning organization? Harv Bus Rev. 2008;86(3):109-116,134.

81. Firth-Cozens J. Organisational trust: the keystone to patient safety. Qual Saf Health Care. 2004;13(1):56-61.

82. Firth-Cozens J. Anxiety as a barrier to risk management. Qual Saf Health Care. 2002;11(2):115.

83. Stocker M, Berger TM. Lernen aus Fehlermeldungen auf der Kinderintensivstation [Learning from a critical incident reporting system in the pediatric intensive care unit]. Anaesthesist. 2015;64(12):968-974. German.

84. Pfeiffer Y, Briner M, Wehner T, Manser T. Motivational antecedents of incident reporting: evidence from a survey of nurses and physicians. Swiss Med Wkly. 2013;143:w13881.

85. Spanu F. Exploiting mistakes as learning opportunities to improve patient safety. Eur Health Psychol. 2012;14(4):85-89.

86. Van der Starre C, van Dijk M, van den Bos A, Tibboel D. Paediatric critical incident analysis: lessons learnt on analysis, recommendations and implementation. Eur J Pediatr. 2014;173(11):1449-1457.

87. Mahajan RP. Critical incident reporting and learning. Br J Anaesth. 2010;105(1):69-75.

88. Pronovost PJ, Thompson DA, Holzmueller CG, et al. Toward learning from patient safety reporting systems. J Crit Care. 2006; 21(4):305-315.

89. Tarrago R, Nowak JE, Leonard CS, Payne NR. Reductions in invasive device use and care costs after institution of a daily safety checklist in a pediatric critical care unit. Jt Comm J Qual Patient Saf. 2014;40(6):270-278.

90. Hollnagel E. Safety-I and Safety-II: The Past and Future of Safety Management. 1st ed. Farnham, Surrey; Burlington, VT: Ashgate Publishing Company; 2014.

91. Weick KE. Organizational culture as a source of high reliability. Calif Manage Rev. 1987;29(2):112-127.

92. Gino F, Pisano GP. Why leaders don't learn from success. Harv Bus Rev. 2011;89(4):68-74,137.

93. National Patient Safety Agency [homepage on the Internet]. Patient Safety First. The Campaign Review. Available from: www. patientsafetyfirst.nhs.uk. Accessed December 29, 2013.

94. Berwick DM, Calkins DR, McCannon CJ, Hackbarth AD. The 100,000 lives campaign: setting a goal and a deadline for improving health care quality. JAMA. 2006;295(3):324-327.

95. Clark G. Organisational culture and safety: an interdependent relationship. Aust Health Rev. 2002;25(6):181-189.

96. Wachter RM. Patient safety at ten: unmistakable progress, troubling gaps. Health Aff (Millwood). 2010;29(1):165-173.
97. Landrigan CP, Parry GJ, Bones CB, Hackbarth AD, Goldmann DA, Sharek PJ. Temporal trends in rates of patient harm resulting from medical care. N Engl J Med. 2010;363(22):2124-2134.

98. Hollnagel E. Chromosome alterations in human solid tumors. In: Braithwaite J, Wears RL, editors. Resilient Health Care. 1st ed. Farnham, Surrey: Ashgate Publishing Company; 2013.

99. Sinek S. Start with Why: How Great Leaders Inspire Everyone to Take Action. Reprint ed. New York, NY: Portfolio; 2011.

100. Sinek S. Leaders Eat Last: Why Some Teams Pull Together and Others Don't. New York, NY: Portfolio; 2014.

101. Block P. Stewardship: Choosing Service Over Self Interest. San Francisco, CA: Berrett-Koehler Publishers; 1996.

102. Firth-Cozens J, Mowbray D. Leadership and the quality of care. Qual Health Care. 2001;10(suppl 2):ii3-ii7.

103. Souba WW. The science of leading yourself: a missing piece in the health care transformation puzzle. Open J Leadersh. 2013; 02(03):45-55.

104. Souba C. Leading again for the first time. J Surg Res. 2009; 157(2):139-153.

105. Carroll JS, Quijada MA. Redirecting traditional professional values to support safety: changing organisational culture in health care. Qual Saf Health Care. 2004;13(suppl 2):ii16-ii21.

106. Rehder KJ, Uhl TL, Meliones JN, Turner DA, Smith PB, Mistry KP. Targeted interventions improve shared agreement of daily goals in the pediatric intensive care unit. Pediatr Crit Care Med. 2012;13(1):6-10.

107. Nelson EC, Batalden PB, Huber TP, et al. Microsystems in health care: part 1. Learning from high-performing front-line clinical units. Jt Comm J Qual Improv. 2002;28(9):472-493.

108. Mohr JJ, Barach P, Cravero JP, et al. Microsystems in health care: part 6. Designing patient safety into the microsystem. Jt Comm J Qual Saf. 2003;29(8):401-408.

109. Deilkås E, Hofoss D. Patient safety culture lives in departments and wards: multilevel partitioning of variance in patient safety culture BMC Health Serv Res. 2010;10:85.

110. Carroll JS, Rudolph JW. Design of high reliability organizations in health care. Qual Saf Health Care. 2006;15(suppl 1):i4-i9.

111. Ness DL, Johnson BH. Dying in America: a constructive step forward and an opportunity to deepen partnerships with patients and families. Ann Intern Med. 2015;162(3):226-227.

112. Salas E, Paige JT, Rosen MA. Creating new realities in healthcare: the status of simulation-based training as a patient safety improvement strategy. BMJ Qual Saf. 2013;22(6):449-452.

113. Salas E, DiazGranados D, Weaver SJ, King H. Does team training work? Principles for health care. Acad Emerg Med. 2008;15(11):1002-1009.

114. Rosen MA, Salas E, Wilson KA, et al. Measuring team performance in simulation-based training: adopting best practices for healthcare. Simul Healthc. 2008;3(1):33-41.

115. Cook DA, Hatala R, Brydges R, et al. Technology-enhanced simulation for health professions education: a systematic review and metaanalysis. JAMA. 2011;306(9):978-988.

116. McGaghie WC, Issenberg SB, Cohen ER, Barsuk JH, Wayne DB. Does simulation-based medical education with deliberate practice yield better results than traditional clinical education? A meta-analytic comparative review of the evidence. Acad Med. 2011;86(6):706-711.

117. Neily J, Mills PD, Young-Xu Y, et al. Association between implementation of a medical team training program and surgical mortality. JAMA. 2010;304(15):1693-1700.

118. Stocker M, Burmester M, Allen M. Optimisation of simulated team training through the application of learning theories: a debate for a conceptual framework. BMC Med Educ. 2014;14(1):69.

119. Rodger S, Mickan S, Marinac J, Woodyatt G. Enhancing teamwork among allied health students: evaluation of an interprofessional workshop. J Allied Health. 2005;34(4):230-235.

120. Featherstone P, Smith GB, Linnell M, Easton S, Osgood VM. Impact of a one-day inter-professional course (ALERT) on attitudes and confidence in managing critically ill adult patients. Resuscitation. 2005;65(3):329-336 
121. Yamani N, Asgarimoqadam M, Haghani F, Alavijeh AQ. The effect of interprofessional education on interprofessional performance and diabetes care knowledge of health care teams at the level one of health service providing. Adv Biomed Res. 2014;3:153.

122. Hammick M, Freeth D, Koppel I, Reeves S, Barr H. A best evidence systematic review of interprofessional education: BEME Guide no. 9. Med Teach. 2007;29(8):735-751.

123. Van Veen-Berkx E, Bitter J, Kazemier G, Scheffer GJ, Gooszen HG. Multidisciplinary teamwork improves use of the operating room: a multicenter study. J Am Coll Surg. 2015;220(6):1070-1076.

124. Kotsakis A, Mercer K, Mohseni-Bod H, Gaiteiro R, Agbeko R. The development and implementation of an inter-professional simulation based pediatric acute care curriculum for ward health care providers. J Interprof Care. 2015;29(4):392-394.

125. Sandahl C, Gustafsson H, Wallin C-J, et al. Simulation team training for improved teamwork in an intensive care unit. Int $J$ Health Care Qual Assur. 2013;26(2):174-188.
126. Stocker M, Allen M, Pool N, et al. Impact of an embedded simulation team training programme in a paediatric intensive care unit: a prospective, single-centre, longitudinal study. Intensive Care Med. 2012;38(1):99-104.

127. Kalén S, Ponzer S, Silén C. The core of mentorship: medical students' experiences of one-to-one mentoring in a clinical environment. $A d v$ Health Sci Educ Theory Pract. 2012;17(3):389-401.

128. Frykman M, Hasson H, Athlin ÅM, von Thiele Schwarz U. Functions of behavior change interventions when implementing multi-professional teamwork at an emergency department: a comparative case study. $B M C$ Health Serv Res. 2014;14:218.

129. Stocker M, Menadue L, Kakat S, et al. Reliability of team-based selfmonitoring in critical events: a pilot study. BMC Emerg Med. 2013; $13: 22$.

130. Tumerman M, Carlson LMH. Increasing medical team cohesion and leadership behaviors using a 360-degree evaluation process. WMJ. 2012;111(1):33-37.

\section{Publish your work in this journal}

The Journal of Multidisciplinary Healthcare is an international, peerreviewed open-access journal that aims to represent and publish research in healthcare areas delivered by practitioners of different disciplines. This includes studies and reviews conducted by multidisciplinary teams as well as research which evaluates the results or conduct of such teams or health- care processes in general. The journal covers a wide range of areas and welcomes submissions from practitioners at all levels, from all over the world. The manuscript management system is completely online and includes a very quick and fair peer-review system. Visit http://www.dovepress.com/ testimonials.php to read real quotes from published authors. 